\title{
Synthesis, photophysical, electrochemical and electroluminescence studies of red emitting phosphorescent Ir(III) heteroleptic complexes
}

\author{
FARMAN ALI ${ }^{\mathrm{a}, \mathrm{b}, *}$, PABITRA K NAYAK ${ }^{\mathrm{a}, \mathrm{c}}, \mathrm{N}^{\text {PERIASAMY }}{ }^{\mathrm{a}, \mathrm{d}}$ and NEERAJ AGARWAL ${ }^{\mathrm{a}, \mathrm{e}, *}$ \\ ${ }^{a}$ Department of Chemical Sciences, Tata Institute of Fundamental Research, Homi Bhabha Road, Colaba, \\ Mumbai 400 005, India \\ ${ }^{\mathrm{b}}$ Department of Applied Chemistry, Aligarh Muslim University, Aligarh, Uttar Pradesh, India \\ ${ }^{\mathrm{c}}$ Clarendon Laboratory, University of Oxford, Oxford OX1 3PU, UK \\ d303, Golf Manor, Wind Tunnel Road, Bengaluru 560 017, India \\ eUM-DAE, Centre for Excellence in Basic Sciences, Health Centre Building, Kalina Campus, Santacruz (E), \\ Mumbai 400 098, India \\ E-mail: farmanali.ac@amu.ac.in; na@cbs.ac.in
}

MS received 21 March 2017; revised 14 June 2017; accepted 3 July 2017; published online 4 September 2017

\begin{abstract}
Five heteroleptic, cyclometalated $\left(\mathrm{C}^{\wedge} \mathrm{N}\right)$ Iridium(III) complexes of acetylacetone (acac) and 1-phenyl-isoquinoline (piq) derivatives, $\operatorname{Ir}(\mathrm{acac})(\mathrm{piq})_{2}, \operatorname{Ir}(\mathrm{acac})(2,4$-difluoro-piq) 2 , $\operatorname{Ir}(\mathrm{acac})$ (4-trifluoromethylpiq) 2 , Ir(acac)(4-N,N-dimethyl-piq)2, Ir(acac)(4-acetyl-piq)2, were synthesized and characterized. The $\left(\mathrm{C}^{\wedge} \mathrm{N}\right)_{2} \operatorname{Ir}(\mathrm{acac})$ complexes in toluene showed phosphorescence $(\lambda \max =598 \mathrm{~nm}$ to $658 \mathrm{~nm})$ with quantum yields $(0.1$ to 0.32$)$ and microsecond lifetimes $(0.43$ to $1.9 \mu \mathrm{s})$. The complexes were non-luminescent in thin films due to self-quenching but luminescent when lightly doped $(5 \%)$ in a host organic material, $4,4^{\prime}$-Bis( $\mathrm{N}$ carbazolyl)-1,1'-biphenyl (CBP). The HOMO levels determined using cyclic voltammetric oxidation potentials were in the range -5.48 to $-5.80 \mathrm{eV}$. Electroluminescence properties and performance of the Ir complexes doped in CBP (active layer) were studied in a multilayer (ITO/F4TCNQ/TPD/doped CBP/BCP/LiF/Al) organic light emitting device (OLED). The electroluminescense (EL) spectra of the device matched with the phosphorescent spectra of the Ir complexes. The turn-on voltage at $\sim 4.5 \mathrm{~V}$, maximum brightness of $7600 \mathrm{~cd} / \mathrm{m}^{2}$ and current efficiency of $\sim 7.0 \mathrm{~cd} / \mathrm{A}$ at a brightness of $\sim 100 \mathrm{~cd} / \mathrm{m}^{2}$ indicate that these are promising OLED materials.
\end{abstract}

Keywords. 1-Phenyl-isoquinoline; Suzuki-Miyaura coupling; Iridium(III)complex; phosphorescence; red emitter; electroluminescence.

\section{Introduction}

Luminescent, homoleptic and heteroleptic Ir(III) complexes consisting of one or more cyclometalating $\left(\mathrm{C}^{\wedge} \mathrm{N}\right)$ ligands are an important class of materials used in electro-phosphorescent organic light emitting devices (OLEDs). ${ }^{1-5}$ The luminescence of the heavy metal complex is due to phosphorescence from the triplet state. The normally forbidden transition between Ground and Triplet state becomes permissible due to spin-orbit coupling strongly induced by the heavy metal. Often, the extinction coefficient (oscillator strength) for singlettriplet transition becomes comparable to singlet-singlet

\footnotetext{
*For correspondence
}

transition. As a result, the radiative rate of phosphorescence from triplet to singlet is enhanced; resulting in decreased lifetime of the triplet state and enhanced luminescence quantum yield at room temperature. ${ }^{6}$ In small molecule based OLEDs, recombination of electrons and holes produces singlet and triplet excitons in 1:3 ratio. The triplet excitons in most organic materials do not contribute to emission and go waste. ${ }^{7}$ Highly phosphorescent molecules like Ir complexes are useful to harvest both singlet and triplet excitons and increase the electroluminescence efficiency. ${ }^{8}$ In spite of these advantages, an Ir complex is rarely used as an active emitting layer because of self-quenching. The Ir complex is optimally doped in an active small molecule host material such that triplets of the host molecule are

Electronic supplementary material: The online version of this article (doi:10.1007/s12039-017-1350-y) contains supplementary material, which is available to authorized users. 
harvested and self-quenching is avoided. Doped electrophosphorescent devices using Ir complexes have yielded nearly $100 \%$ internal efficiency. ${ }^{9}$ Nearly $16 \%$ external efficiency has been reported in white light emitting devices using doped electro-phosphorescent material. ${ }^{10}$

The emission colour of an Ir Complex is tuneable in different ways like changing $\mathrm{C}^{\wedge} \mathrm{N}$ ligand structure in a homoleptic complex and by changing ancillary ligand in a hetroleptic complex. ${ }^{11-14}$ A number of studies have revealed a wealth of information on the photophysical, electrochemical, and electroluminescence properties of a large number of Ir complexes, apart from valuable information on synthetic routes and theoretical studies on these molecules. ${ }^{15-17}$ Among the many cyclometalating ligands, it is shown that Ir complex of 1-phenyl isoquinoline (piq) has superior performance in electroluminescence. For example, PL quantum yield of $\operatorname{Ir}(\text { piq })_{3}$ was 0.32 in toluene ${ }^{18}$ and in OLEDs using $\operatorname{Ir}(\text { piq })_{3}$ as dopant, EL brightness of $11,000 \mathrm{~cd} / \mathrm{m}^{2}$ has been reported. ${ }^{19}$ The power efficiency and EQE are of $8.0 \mathrm{~lm} / \mathrm{W}$ and $10.3 \%$ at a brightness of $100 \mathrm{~cd} / \mathrm{m}^{2}$ have been reported. ${ }^{20}$ Similarly, good performance was observed in heteroleptic complex of $\operatorname{Ir}(\mathrm{piq})_{2} \mathrm{X}^{21}$

Another way of tuning emission colour of an Ir complex is by introducing electron donating and withdrawing group in the cyclometalating ligand. ${ }^{22} \mathrm{~A}$ few derivatives of piq have been synthesized and PL and EL properties studied. In this work, we report the synthesis of five heteroleptic Ir complexes. The photophysical and electrochemical properties of these complexes are compared with $\operatorname{Ir}(\mathrm{piq})_{2}$ (acac). Electroluminescence of one Ir complex(2) is also reported.

\section{Experimental}

\subsection{Materials and measurements}

All the solvents, $\mathrm{Na}_{2} \mathrm{CO}_{3}$ and $\mathrm{K}_{2} \mathrm{CO}_{3}$ were obtained from SD Fine Chemicals (India). $\mathrm{IrCl}_{3}$, 1-chloroisoqinoline, acetylacetone and 2-ethoxyethanol were purchased from SigmaAldrich and were used as received. $\mathrm{F}_{4} \mathrm{TCNQ}, \mathrm{BCP}, \mathrm{CBP}$, $\mathrm{TPD}, \mathrm{Pd}\left(\mathrm{PPh}_{3}\right)_{4}$ and aryl boronic acids were purchased from Sigma-Aldrich. Reactions that require anhydrous conditions were carried out under an inert atmosphere of nitrogen. The progress of the reaction was monitored using Silica Gel TLC plates by UV detection (254 and $365 \mathrm{~nm}$ ). Silica gel (100200 mesh) was used for column chromatography. Melting points (uncorrected) were measured using a capillary melting point apparatus. ${ }^{1} \mathrm{H}$ and ${ }^{13} \mathrm{C}$ NMR spectra were recorded using Bruker spectrometer with working frequency $500 \mathrm{MHz}$ for ${ }^{1} \mathrm{H}$ NMR and $125 \mathrm{MHz}$ for ${ }^{13} \mathrm{C}$ NMR. For ${ }^{1} \mathrm{H}$ NMR and ${ }^{13} \mathrm{C}$ NMR, the chemical shifts were referenced to $\mathrm{CH}_{2} \mathrm{Cl}_{2}$ or $\mathrm{CHCl}_{3}$ present as an impurity in the deuterated solvent. Mass spectra were measured using a Thermo Finnigan LCQ
Deca Electrospray quadrupole ion trap mass spectrometer (Thermo Electron Co., Hemel Hempstead, Herts, UK) or on MALDI-TOF (Micromass Tof Spec 2E). Photoluminescence was measured using SPEX Fluorolog 1681. Cyclic voltammetry was done using CH Instruments 600C.

\subsection{Synthesis}

2.2a General method for the synthesis of ligands: Compounds 6-10 (see Figure 1 for the synthetic scheme and structures of molecules 1-10) were synthesized by the SuzukiMiyaura coupling. ${ }^{23,24}$ In a screw cap reaction vial charged with 1-chloroisoquinoline (1.0 mmol), aryl boronic acid (1.2 $\mathrm{mmol}), \mathrm{K}_{2} \mathrm{CO}_{3}(5.0 \mathrm{mmol})$ and $\mathrm{Pd}\left(\mathrm{PPh}_{3}\right)_{4}(0.05 \mathrm{mmol}), 1,2-$ dimethoxyethane (DME) $(3.0 \mathrm{~mL})$ and water $(3.0 \mathrm{~mL})$ were added and the reaction mixture was refluxed under nitrogen atmosphere for $20 \mathrm{~h}$. On completion of the reaction, water was added and the organic phase was separated. The aqueous layer was washed thrice with ethyl acetate. All the organic layers were combined and washed with water, brine and dried over anhydrous sodium sulphate. The crude product was purified by column chromatography using hexanes and ethyl acetate as eluent. Pure compounds 6-10 were obtained as solid in $73-92 \%$ yield.

2.2.1 a 6: Yield: 0.19 g $(92 \%)$; M.p.: $95^{\circ} \mathrm{C} .{ }^{1} \mathrm{H}$ NMR $(500$ $\left.\mathrm{MHz}, \mathrm{CDCl}_{3}\right): \delta \mathrm{ppm} 7.54(\mathrm{~m}, 4 \mathrm{H}), 7.69(\mathrm{~m}, 4 \mathrm{H}), 7.89(\mathrm{~d}, 1 \mathrm{H}$, $J=8 \mathrm{~Hz}), 8.11(\mathrm{~d}, 1 \mathrm{H}, J=8.5 \mathrm{~Hz}), 8.61(\mathrm{~d}, 1 \mathrm{H}, J=5.5 \mathrm{~Hz})$. ${ }^{13} \mathrm{C}$ NMR $\left(125 \mathrm{MHz}, \mathrm{CDCl}_{3}\right) \delta \mathrm{ppm} 119.81,120.00,126.7$, $126.88,127.12,127.52,127.64,128.32,128.54,129.79$, 129.99, 136.84, 142.13, 142.28. ES-MS (m/z) for $\mathrm{C}_{15} \mathrm{H}_{11} \mathrm{~N}$ Calcd. 205.26; Obsd. $206.22(\mathrm{M}+1)^{+}$.

2.2.1b 7: Yield: $0.19 \mathrm{~g}(79 \%)$; M.p.: $80^{\circ} \mathrm{C} .{ }^{1} \mathrm{H}$ NMR $(500$ $\left.\mathrm{MHz}, \mathrm{CDCl}_{3}\right): \delta \mathrm{ppm} 7.0(\mathrm{~m}, 2 \mathrm{H}), 7.57(\mathrm{~m}, 2 \mathrm{H}), 7.71(\mathrm{~m}, 2 \mathrm{H})$, $7.78(\mathrm{~m}, 1 \mathrm{H}), 7.9(\mathrm{~d}, 1 \mathrm{H}, J=8.5 \mathrm{~Hz}), 8.63(\mathrm{~d}, 1 \mathrm{H}, J=5.5$ $\mathrm{Hz}) .{ }^{13} \mathrm{C}$ NMR $\left(125 \mathrm{MHz}, \mathrm{CDCl}_{3}\right) \delta \mathrm{ppm} 103.96,104.17$, $104.38,111.66,111.83,120.8,126.93,126.98,127.52$, $130.29,132.79,132.82,132.86,142.32,142.35$. ES-MS (m/z) for $\mathrm{C}_{15} \mathrm{H}_{9} \mathrm{~F}_{2} \mathrm{~N}$ Calcd. 241.24; Obsd. $242.26(\mathrm{M}+1)^{+}$.

2.2.1c 8: Yield: $0.20 \mathrm{~g}(73 \%)$; M.p.: $120^{\circ} \mathrm{C} .{ }^{1} \mathrm{H}$ NMR (500 $\left.\mathrm{MHz}, \mathrm{CDCl}_{3}\right) \delta \mathrm{ppm} 7.57(\mathrm{t}, 1 \mathrm{H}, J=7.0 \mathrm{~Hz}), 7.71(\mathrm{~m}, 2 \mathrm{H})$, $7.82(\mathrm{~m}, 4 \mathrm{H}), 7.92(\mathrm{~d}, 1 \mathrm{H}, J=8.0 \mathrm{~Hz}), 8.02(\mathrm{~d}, 1 \mathrm{H}, J=8.5$ $\mathrm{Hz}), 8.63(\mathrm{~d}, 1 \mathrm{H}, J=5.0 \mathrm{~Hz}) .{ }^{13} \mathrm{C}$ NMR $\left(125 \mathrm{MHz}, \mathrm{CDCl}_{3}\right) \delta$ ppm 28.81, 120.56, 125.31, 125.34, 126.53, 126.91, 127.18, $127.59,130.25,130.28,136.84,142.24,142.28,143.09$, 159.13. ES-MS (m/z) for $\mathrm{C}_{16} \mathrm{H}_{10} \mathrm{~F}_{3} \mathrm{~N}$ Calcd. 273.26; Obsd. $274.27(\mathrm{M}+1)^{+}$.

2.2.1d 9: Yield: $0.22 \mathrm{~g}(83 \%)$; M.p.: $101^{\circ} \mathrm{C} .{ }^{1} \mathrm{H}$ NMR (500 $\left.\mathrm{MHz}, \mathrm{CDCl}_{2}\right) \delta \mathrm{ppm} 3.04(\mathrm{~s}, 6 \mathrm{H}), 6.87(\mathrm{~d}, 2 \mathrm{H}, J=8.5$ $\mathrm{Hz}), 7.52(\mathrm{~m}, 1 \mathrm{H}), 7.56(\mathrm{~d}, 1 \mathrm{H}, J=6.0 \mathrm{~Hz}), 7.65-7.67(\mathrm{~m}$, $3 \mathrm{H}), 7.85(\mathrm{~d}, 1 \mathrm{H}, J=8.0 \mathrm{~Hz}), 8.25(\mathrm{~d}, 1 \mathrm{H}, J=8.0 \mathrm{~Hz})$, $8.6(\mathrm{~d}, 1 \mathrm{H}, J=6.0 \mathrm{~Hz}) \cdot{ }^{13} \mathrm{C} \mathrm{NMR}\left(125 \mathrm{MHz}, \mathrm{CDCl}_{3}\right) \delta$ ppm 40.19, 111.67, 115.03, 115.88, 118.76, 126.60, 126.77, $126.84,127.23,127.69$, 127.76, 129.69, 131.06, 137.01, $142.07,150.82,160.70$. MALDI-TOF $(\mathrm{m} / \mathrm{z})$ for $\mathrm{C}_{17} \mathrm{H}_{16} \mathrm{~N} 2$ Calcd. 248.33; Obsd. $248.43\left(\mathrm{M}^{+}\right)$. 


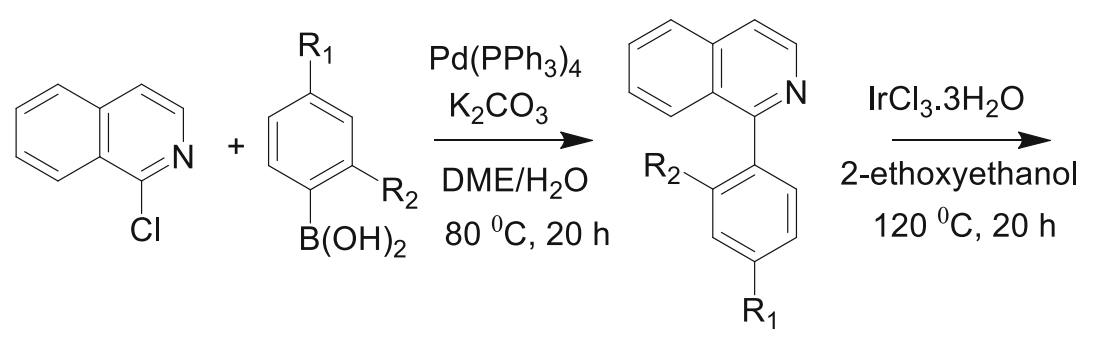

$\mathrm{R}_{1}=\mathrm{H}, \mathrm{R}_{2}=\mathrm{H} ; 6(92 \%)$

$\mathrm{R}_{1}=\mathrm{F}, \mathrm{R}_{2}=\mathrm{F} ; 7(79 \%)$

$\mathrm{R}_{1}=\mathrm{CF}_{3}, \mathrm{R}_{2}=\mathrm{H} ; 8$ (73\%)

$\mathrm{R}_{1}=\mathrm{N}\left(\mathrm{CH}_{3}\right)_{2}, \mathrm{R}_{2}=\mathrm{H} ; 9(83 \%)$

$\mathrm{R}_{1}=\mathrm{COCH}_{3}, \mathrm{R}_{2}=\mathrm{H} ; 10(80 \%)$

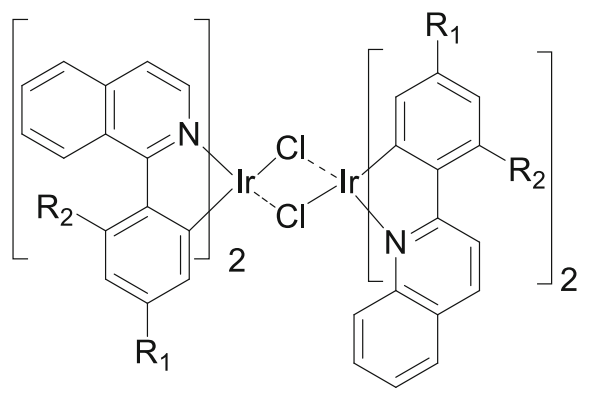

$$
\begin{aligned}
& \mathrm{R}_{1}=\mathrm{H}, \mathrm{R}_{2}=\mathrm{H} ;(35 \%) \\
& \mathrm{R}_{1}=\mathrm{F}, \mathrm{R}_{2}=\mathrm{F} ;(67 \%) \\
& \mathrm{R}_{1}=\mathrm{CF}_{3}, \mathrm{R}_{2}=\mathrm{H} ;(37 \%) \\
& \mathrm{R}_{1}=\mathrm{N}\left(\mathrm{CH}_{3}\right)_{2}, \mathrm{R}_{2}=\mathrm{H} ;(84 \%) \\
& \mathrm{R}_{1}=\mathrm{COCH}_{3}, \mathrm{R}_{2}=\mathrm{H} ;(65 \%)
\end{aligned}
$$
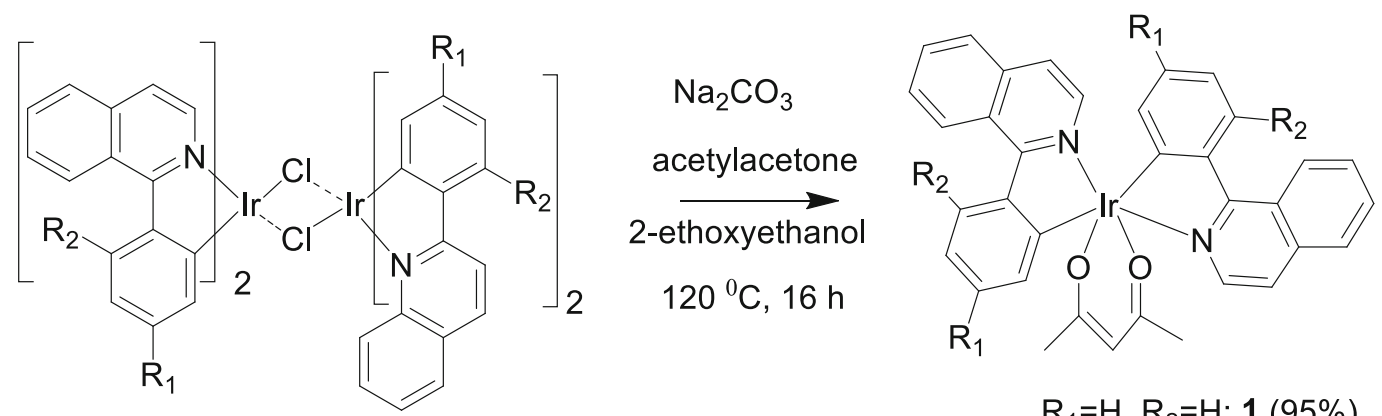

$$
\begin{aligned}
& \mathrm{R}_{1}=\mathrm{H}, \mathrm{R}_{2}=\mathrm{H} ; \mathbf{1}(95 \%) \\
& \mathrm{R}_{1}=\mathrm{F}, \mathrm{R}_{2}=\mathrm{F} ; \mathbf{2}(93 \%) \\
& \mathrm{R}_{1}=\mathrm{CF}_{3}, \mathrm{R}_{2}=\mathrm{H} ; \mathbf{3}(32 \%) \\
& \mathrm{R}_{1}=\mathrm{N}\left(\mathrm{CH}_{3}\right)_{2}, \mathrm{R}_{2}=\mathrm{H} ; \mathbf{4}(82 \%) \\
& \mathrm{R}_{1}=\mathrm{COCH}_{3}, \mathrm{R}_{2}=\mathrm{H} ; \mathbf{5}(98 \%)
\end{aligned}
$$

Figure 1. Synthetic route to prepare the $\operatorname{Ir}(\mathrm{III})$ complexes, 1-5.

2.2.1e 10: Yield: $0.20 \mathrm{~g}(80 \%)$; M.p.: $100^{\circ} \mathrm{C} .{ }^{1} \mathrm{H}$ NMR $\left(500 \mathrm{MHz}, \mathrm{CDCl}_{3}\right) \delta \mathrm{ppm} 2.70\left(\mathrm{~s}, 3 \mathrm{H}, \mathrm{CH}_{3}\right), 7.56(\mathrm{t}, 1 \mathrm{H}$, $J=8.0 \mathrm{~Hz}), 7.7(\mathrm{~m}, 2 \mathrm{H}), 7.82(\mathrm{~d}, 2 \mathrm{H}, J=8.0 \mathrm{~Hz}), 7.91$ $(\mathrm{d}, 1 \mathrm{H}, J=8.5 \mathrm{~Hz}), 8.04(\mathrm{~d}, 1 \mathrm{H}, J=8.5 \mathrm{~Hz}), 8.13(\mathrm{~d}, 2 \mathrm{H}$, $J=8.5 \mathrm{~Hz}), 8.63(\mathrm{~d}, 1 \mathrm{H}, J=5.5 \mathrm{~Hz}) .{ }^{13} \mathrm{C} \mathrm{NMR}(125 \mathrm{MHz}$, $\left.\mathrm{CDCl}_{3}\right) \delta \mathrm{ppm} 26.76,107.5,120.46,120.51,126.95,127.12$, $127.51,128.32,128.38,130.19,136.83,136.93,142.23$, 142.29, 144.14, 159.42, 197.97. ES-MS (m/z) for $\mathrm{C}_{17} \mathrm{H}_{13} \mathrm{NO}$ Calcd. 248.30; Obsd. $248.26\left(\mathrm{M}^{+}\right)$.

2.2b General method for the synthesis of Ir(III) heteroleptic complexes: One of the ligands (6-10) $(2.0$ $\mathrm{mmol}), \mathrm{IrCl}_{3}(1.0 \mathrm{mmol})$ were dissolved in 2-ethoxyethanol $(2.0 \mathrm{~mL})$ and water $(1.0 \mathrm{~mL})$. The reaction mixture was refluxed at $120^{\circ} \mathrm{C}$ for $16 \mathrm{~h}$. The solvent was evaporated under reduced pressure, and the solid residue was washed three times with methanol. The solid product ( $\mu$-chloro bridged dimer) was dried in vacuum. The $\mu$-chloro dimer $(1.0 \mathrm{mmol})$, acetylacetone $(2.2 \mathrm{mmol}), \mathrm{Na}_{2} \mathrm{CO}_{3}(10.0 \mathrm{mmol})$ and 2ethoxyethanol $(3.0 \mathrm{~mL})$ were mixed and refluxed for $16 \mathrm{~h}$ at $120^{\circ} \mathrm{C}$. The solvent was evaporated under vacuum and the resulted solid residue was washed three times with methanol to afford pure 1-5 as coloured solid in 32-98\% yields.
2.2.2 a Characterization data for 1 : Yield: $0.33 \mathrm{~g}(95 \%) .{ }^{1} \mathrm{H}$ NMR $\left(500 \mathrm{MHz}, \mathrm{CDCl}_{3}\right) \delta \mathrm{ppm} 1.25\left(\mathrm{~s}, 6 \mathrm{H}, \mathrm{CH}_{3}\right), 5.20(\mathrm{~s}$, $1 \mathrm{H}, \mathrm{CH}), 6.38(\mathrm{~d}, 2 \mathrm{H}, J=7.0 \mathrm{~Hz}), 6.65(\mathrm{t}, 2 \mathrm{H}, J=7.5 \mathrm{~Hz})$, $6.89(\mathrm{t}, 2 \mathrm{H}, J=7.0 \mathrm{~Hz}), 7.47(\mathrm{~d}, 2 \mathrm{H}, J=6.5 \mathrm{~Hz}), 7.71(\mathrm{~m}$, $4 \mathrm{H}), 7.94(\mathrm{~m}, 2 \mathrm{H}), 8.20(\mathrm{~d}, 2 \mathrm{H}, J=8.0 \mathrm{~Hz}), 8.45(\mathrm{~d}, 2 \mathrm{H}, J=$ $6.5 \mathrm{~Hz}), 8.98(\mathrm{~m}, 2 \mathrm{H})$. MALDI-TOF $(\mathrm{m} / \mathrm{z})$ for $\mathrm{C}_{35} \mathrm{H}_{27} \mathrm{~N}_{2} \mathrm{O}_{2} \mathrm{Ir}$ Calcd. 699.83; Obsd. $699.94\left(\mathrm{M}^{+}\right), 601.10\left(\mathrm{M}^{+}\right.$-acac).

2.2.2b Characterization data for 2 : Yield: $0.36 \mathrm{~g}(93 \%) .{ }^{1} \mathrm{H}$ NMR (500 MHz, $\left.\mathrm{CDCl}_{3}\right) \delta$ ppm $1.76\left(\mathrm{~s}, 6 \mathrm{H}, \mathrm{CH}_{3}\right), 5.22(\mathrm{~s}$, $1 \mathrm{H}, \mathrm{CH}), 5.73(\mathrm{~d}, 2 \mathrm{H}, J=8.5 \mathrm{~Hz}), 6.41(\mathrm{t}, 2 \mathrm{H}, J=10.0$ $\mathrm{Hz}), 7.59(\mathrm{~d}, 2 \mathrm{H}, J=6.5 \mathrm{~Hz}), 7.66(\mathrm{t}, 2 \mathrm{H}, J=7.5 \mathrm{~Hz})$, $7.74(\mathrm{t}, 2 \mathrm{H}, J=8.0 \mathrm{~Hz}), 7.91(\mathrm{~d}, 2 \mathrm{H}, J=8.0 \mathrm{~Hz}), 8.32$ $(\mathrm{d}, 2 \mathrm{H}, J=6.0 \mathrm{~Hz}), 8.41(\mathrm{~m}, 2 \mathrm{H})$. MALDI-TOF $(\mathrm{m} / \mathrm{z})$ for $\mathrm{C}_{35} \mathrm{H}_{23} \mathrm{~N}_{2} \mathrm{O}_{2} \mathrm{~F}_{4}$ Ir Calcd. 771.79; Obsd. $772.30\left(\mathrm{M}^{+}\right), 673.34$ $\left(\mathrm{M}^{+}\right.$-acac).

2.2.2c Characterization data for 3 : Yield: $0.13 \mathrm{~g}(32 \%) .{ }^{1} \mathrm{H}$ $\operatorname{NMR}\left(500 \mathrm{MHz}, \mathrm{CDCl}_{3}\right) \delta \mathrm{ppm} 1.8(\mathrm{~s}, 6 \mathrm{H}), 6.57(\mathrm{~s}, 2 \mathrm{H}), 7.21$ $(\mathrm{d}, 2 \mathrm{H}, J=8.5 \mathrm{~Hz}), 7.69(\mathrm{~d}, 2 \mathrm{H}, J=6.5 \mathrm{~Hz}), 7.84(\mathrm{~m}, 4 \mathrm{H})$, $8.1(\mathrm{~m}, 2 \mathrm{H}), 8.37(\mathrm{~d}, 2 \mathrm{H}, J=8.5 \mathrm{~Hz}), 8.48(\mathrm{~d}, 2 \mathrm{H}, J=6.5$ $\mathrm{Hz}), 8.99(\mathrm{~m}, 2 \mathrm{H})$. MALDI-TOF (m/z) for $\mathrm{C}_{37} \mathrm{H}_{25} \mathrm{~N}_{2} \mathrm{O}_{2} \mathrm{~F}_{6} \mathrm{Ir}$ Calcd. 835.83; Obsd.836. $19\left(\mathrm{M}^{+}\right), 737.30\left(\mathrm{M}^{+}\right.$-acac). 
2.2.2d Characterization data for 4: Yield: $0.32 \mathrm{~g} \mathrm{(82 \% ).}$ ${ }^{1} \mathrm{H}$ NMR $\left(500 \mathrm{MHz}, \mathrm{CDCl}_{3} \delta \mathrm{ppm} 1.58(\mathrm{~s}, 6 \mathrm{H}), 1.84(\mathrm{~s}, 6 \mathrm{H})\right.$, $2.60(\mathrm{~s}, 6 \mathrm{H}), 5.55(\mathrm{~s}, 1 \mathrm{H}), 6.36-6.37(\mathrm{~m}, 2 \mathrm{H}), 7.35(\mathrm{~m}, 2 \mathrm{H})$, $7.67(\mathrm{~m}, 4 \mathrm{H}), 7.90(\mathrm{~d}, 2 \mathrm{H}, \mathrm{J}=7.5 \mathrm{~Hz}), 8.04(\mathrm{~m}, 4 \mathrm{H}), 8.36(\mathrm{~d}$, $2 \mathrm{H}, J=6.0 \mathrm{~Hz}), 8.87(\mathrm{~d}, 2 \mathrm{H}, J=8.5 \mathrm{~Hz})$. MALDI-TOF $(\mathrm{m} / \mathrm{z})$ for $\mathrm{C}_{39} \mathrm{H}_{37} \mathrm{~N}_{4} \mathrm{O}_{2} \mathrm{Ir}$ Calcd. 785.97; Obsd.785.40 $\left(\mathrm{M}^{+}\right)$, $686.62\left(\mathrm{M}^{+}\right.$-acac $)$.

2.2.2e Characterization data for 5: Yield: $0.40 \mathrm{~g}(98 \%)$. ${ }^{1} \mathrm{H}$ NMR $\left(500 \mathrm{MHz}, \mathrm{CDCl}_{3}\right) \delta \mathrm{ppm} 1.78\left(\mathrm{~s}, 6 \mathrm{H}, \mathrm{CH}_{3}\right), 2.10$ $\left(\mathrm{s}, 6 \mathrm{H}, \mathrm{CH}_{3}\right), 5.25(\mathrm{~s}, 1 \mathrm{H}, \mathrm{CH}), 6.86(\mathrm{~s}, 2 \mathrm{H}), 7.47(\mathrm{~m}, 2 \mathrm{H})$, $7.62(\mathrm{~d}, 2 \mathrm{H}, J=6.0 \mathrm{~Hz}), 7.77(\mathrm{~m}, 4 \mathrm{H}), 7.99(\mathrm{~m}, 2 \mathrm{H}), 8.26$ $(\mathrm{d}, 2 \mathrm{H}, J=8.5 \mathrm{~Hz}), 8.52(\mathrm{~d}, 2 \mathrm{H}, J=6.0 \mathrm{~Hz}), 8.96(\mathrm{~m}, 2 \mathrm{H})$. MALDI-TOF (m/z) for $\mathrm{C}_{39} \mathrm{H}_{31} \mathrm{~N}_{2} \mathrm{O}_{4}$ Ir Calcd. 783.90; Obsd. $783.76\left(\mathrm{M}^{\mathrm{n}+}\right), 684.84\left(\mathrm{M}^{+}\right.$-acac $)$.

\subsection{OLED fabrication and device measurements}

Multilayer structure OLED devices, namely, ITO/F 4 TCNQ/ TPD/CBP + Ir Complex/BCP/LiF/Al, were fabricated on pre-patterned, pre-cleaned ITO-coated glass substrates. The substrate was patterned using standard lithography and then cleaned by mechanical scrubbing with detergent, followed by ultrasonic cleaning in hot water. It was then blow dried using dry $\mathrm{N}_{2}$ gas and was finally UV exposed for $10 \mathrm{~min}$. Organic layers were deposited one after another by thermal evaporation of organic materials kept in separate quartz crucibles in a high vacuum $\left(\sim 10^{-6}\right.$ torr $)$ chamber. The doped layer of CBP with Ir complex (5\% wt/wt) was deposited by simultaneously evaporating the CBP and Ir complex from their respective boats. The deposition rates were controlled with two independent quartz crystals near the respective sources and one near the substrate to monitor the film thickness. LiF and $\mathrm{Al}$ layers were deposited without breaking the vacuum. The thermal evaporation system was fitted with five evaporation sources. In one experiment, five different layers can be evaporated without breaking the vacuum. A thick layer of LiF $(100 \mathrm{~nm})$ was deposited on top of $\mathrm{Al}$ cathode as capping layer. After fabrication, the devices were transferred to another vacuum apparatus fitted with probes for measurements, which resulted in a brief exposure of the device to air. The current (I), voltage (V) and EL (L) characteristics of the OLEDs were measured in vacuum using a Keithley 617 programmable electrometer. EL intensity $\left(\mathrm{cd} / \mathrm{m}^{2}\right)$ measurement was done using a large area calibrated silicon photodiode and fixed geometry of device and detector. EL spectra were measured using a monochromator and Photomultiplier Tube (S-20 response) operated at $720 \mathrm{~V}$.

\section{Results and Discussion}

\subsection{Synthesis}

Iridium complexes 1-5 were synthesized as shown in Figure 1. The ligands 6-10 were synthesized by the Suzuki-Miyaura coupling. ${ }^{23,24} 1$-Chloroisoquinoline
(1.0 mmol), aryl boronic acid (1.2 mmol), $\mathrm{K}_{2} \mathrm{CO}_{3}(5.0$ $\mathrm{mmol})$ and $\mathrm{Pd}\left(\mathrm{PPh}_{3}\right)_{4}(0.05 \mathrm{mmol})$ were refluxed in $\mathrm{DME} /$ water under nitrogen atmosphere for $20 \mathrm{~h}$. On completion of the reaction, the crude product was purified by column chromatography to get pure compounds 6-10 as solid in 73-92\% yield. To synthesize the Iridium complexes, one of the ligands $\mathbf{6}-\mathbf{1 0}$ and $\mathrm{IrCl}_{3}(2: 1$ molar ratio) were refluxed in 2-ethoxyethanol $(2.0 \mathrm{~mL})$ and water $(1.0 \mathrm{~mL})$ mixture for $16 \mathrm{~h} .{ }^{19}$ On evaporation of the solvents and washing the solid residue with methanol, $\mu$-chloro bridged dimer was obtained as solid. The $\mu$ chloro dimer $(1.0 \mathrm{mmol})$, acetylacetone $(2.2 \mathrm{mmol})$, $\mathrm{Na}_{2} \mathrm{CO}_{3}$ were refluxed in 2-ethoxyethanol for $16 \mathrm{~h}$. The solvent was evaporated under vacuum and the resulted solid residue was washed three times with methanol to afford pure 1-5 as coloured solid in 32-98\% yields. The obtained solids were characterized by NMR, mass methods.

\subsection{Absorption and emission studies}

Absorption spectra of 1-5 in dichloromethane are shown in Figure 2. The emission spectra of 1-5 excited at the absorption peak are shown in Figure 3. The excitation

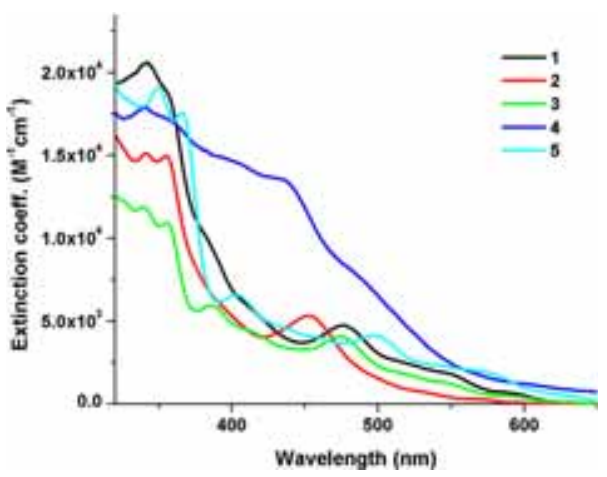

Figure 2. Absorption spectra of 1-5 reco rded in dichloromethane.

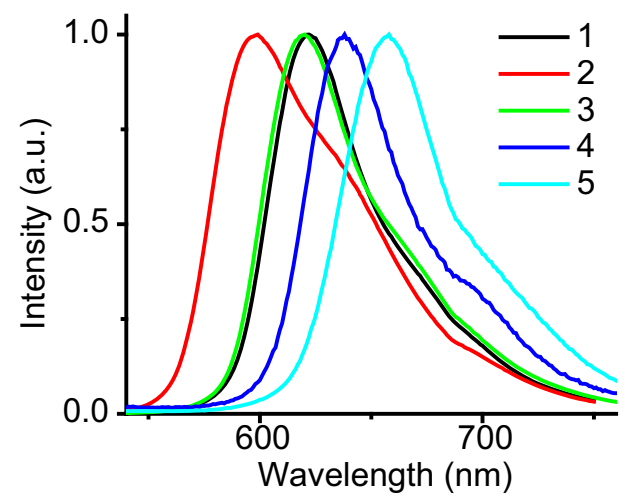

Figure 3. Peak normalized emission spec tra of $\operatorname{Ir}(\mathrm{III})$ complexes 1-5 in toluene. 
spectra (not shown) were similar to the absorption spectra. The optical spectra of Ir complexes have been studied experimentally and theoretically. ${ }^{11-16}$ The absorption spectra in the UV-Visible region consist singlet and triplet transitions of the type $\pi-\pi^{*}$ and MLCT. The normally forbidden triplet transition is strongly allowed to such an extent that the extinction coefficients of ${ }^{3} \pi-\pi^{*}$ and ${ }^{3}$ MLCT are comparable to the corresponding singlet transitions in some complexes. ${ }^{15}$ The absorption spectra are thus broad and multiple peaks are commonly observed. Spectra of $\pi-\pi^{*}$ transitions may have vibrational structures characteristic of the ligand whereas these are absent in MLCT transitions. The absorption spectra of 1-5 have the above common features. The spectral peaks were identified from the derivative spectra and the peak wavelengths and extinction coefficients are summarized in Table 1. The absorption spectrum of $\mathbf{4}$ (N,N-dimethyl derivative) is almost featureless and different from others whereas its emission spectrum was similar to that of others. The excitation spectrum was also similarly featureless indicating that the unusual absorption spectrum of $\mathbf{4}$ is not due to aggregates or impurities.

Ir complexes are weakly luminescent in aerated solution because of oxygen quenching of the long-lived (microseconds) triplet emitting state. Therefore, $\mathrm{N}_{2}$ saturated dilute solutions of $\mathbf{1 - 5}$ in toluene were used to record the emission spectra (Figure 3). Phosphorescence spectra originating from ${ }^{3}$ MLCT are generally broad and featureless in comparison to emission from ${ }^{3 \pi}-\pi^{*}$ state. ${ }^{11,15}$ Emission spectra of $\mathbf{1}-\mathbf{5}$ were broad and featureless which indicate the ${ }^{3}$ MLCT as the lowest excited state in these complexes. Though absorption and excitation spectra of $\mathbf{4}$ are different from those of other molecules, the emission spectra of all the molecules were similar except for the shift in the luminescence maxima. The parent molecule $\mathbf{1}$ has an emission peak at $622 \mathrm{~nm}$, in $\mathbf{2}$ and $\mathbf{3}$ they are blue shifted by 24 and 3 $\mathrm{nm}$, respectively, and in $\mathbf{4}$ and $\mathbf{5}$ they are red shifted by 18 and $36 \mathrm{~nm}$, respectively.

The Ir(III) complexes are almost non-luminescent as solid thin films due to self-quenching. However, they are highly luminescent when doped lightly in 4,4-N,N'dicarbazole-biphenyl (CBP) as the host material. Thin films of 1-5 were prepared on quartz plate using 5\% (w/w) Ir(III) complexes in CBP by spin coating method. Figure 4 shows the emission spectra recorded by exciting CBP at $295 \mathrm{~nm}$. The emission spectra of the thin films were identical to the spectra obtained during direct excitation of Ir complexes at their corresponding absorption peaks (see Figure 3) which indicate that efficient energy transfer occurs from the excited state of host CBP to the dopant Ir complex.

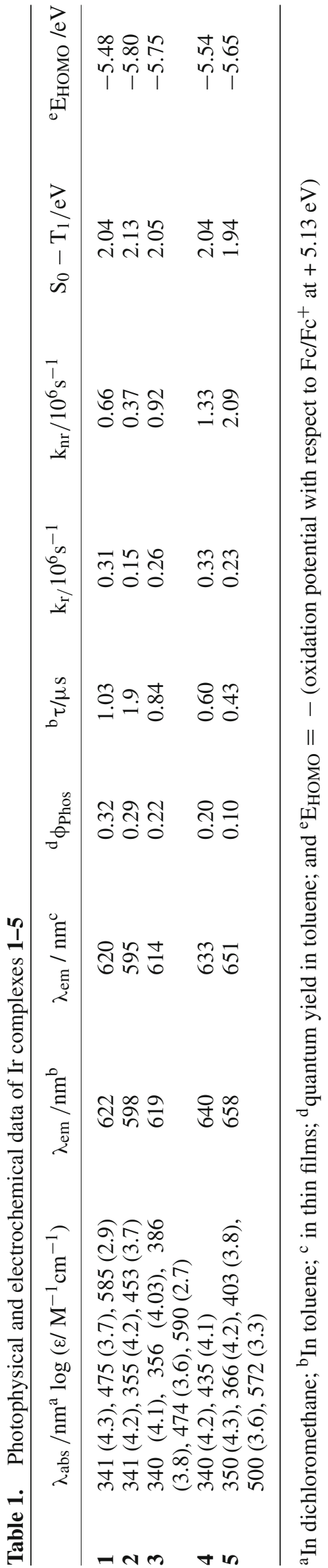




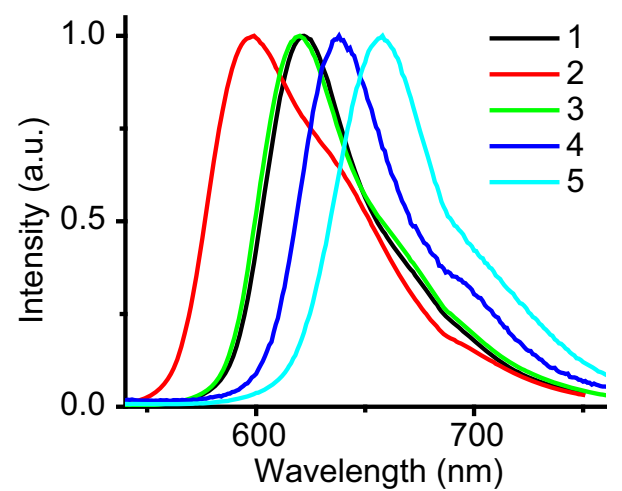

Figure 4. Peak normalized emission spec tra of Ir(III) complexes 1-5 in thin films.

The phosphorescence quantum yields $\left(\phi_{\text {Phos }}\right)$ of the Ir(III) complexes in toluene were obtained using rhodamine $6 \mathrm{G}$ as a standard. ${ }^{27}$ The quantum yields varied from 0.1 to 0.32 for $\mathbf{1}$ to $\mathbf{5}$. $\phi_{\text {Phos }}$ of $\mathbf{2}$ and $\mathbf{3}$ were higher as compared to $\mathbf{4}$ and $\mathbf{5}$.

The Ir(III) complexes 1-5 showed single exponential photoluminescence decay in dry toluene with lifetime varying from 0.43 to $1.9 \mu \mathrm{s}$. These values are comparable to other heteroleptic Ir complexes. ${ }^{18}$

The radiative and non-radiative rate constants were calculated by using the following equations, assuming intersystem crossing yield, $\phi_{\text {isc }}=1$. The value of $\phi_{\text {Phos }}$, $\mathrm{k}_{\mathrm{r}}, \mathrm{k}_{\mathrm{nr}}$ listed in Table 1 are comparable to the values reported for other Ir complexes. ${ }^{18}$

$$
\begin{aligned}
\mathrm{k}_{\mathrm{r}} & =\underset{\text { Phos }}{\phi /(\phi \tau)} \underset{\text { isc }}{ } \\
\mathrm{k}_{\mathrm{nr}} & =(1 / \tau)-\mathrm{k}_{\mathrm{r}}
\end{aligned}
$$

\subsection{Electrochemical properties}

Cyclic voltammetric redox potentials provide insight into the HOMO and LUMO levels and stability of the radical anion/cation. Cyclic voltammetry of the molecules $(\sim 1 \mathrm{mM})$ were done in $\mathrm{CH}_{2} \mathrm{Cl}_{2}$ using tetrabutyl ammoniumhexafluorophosphate $(0.1 \mathrm{M})$ as supporting electrolyte using $\mathrm{Ag} / \mathrm{AgNO}_{3}$ as a reference electrode and ferrocene as an internal reference molecule. Ir(III) complexes 1-5 showed characteristics of reversible oxidation process in cyclic voltammetry (Figure 5 and Figure S11 in Supplementary Information). The peak potentials were determined with respect to ferrocene as an internal standard. The HOMO levels of 1-5 were determined from the corresponding oxidation peak potentials using the reported equations ${ }^{28-30}$ and the values are summarized in Table 1. The HOMO levels of these $\operatorname{Ir}(\mathrm{III})$ complexes lie in the range of -5.48 to $-5.80 \mathrm{eV}$.

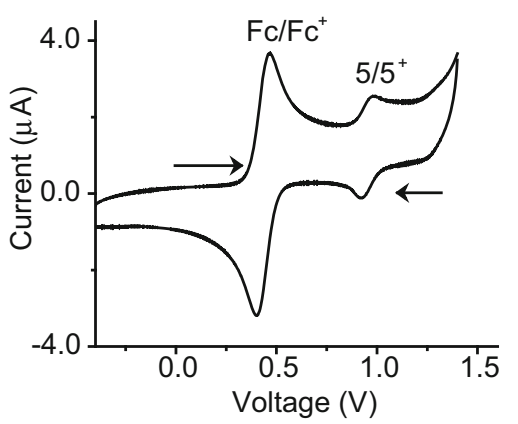

Figure 5. Cyclic voltammogram of 5 recorded in dichloromethane at a scan rate of $100 \mathrm{mV} / \mathrm{s}$ using tetrabutylammoniumhexafluorophosphate (TBAHFP) as supporting electrolyte; Ferrocene $(\mathrm{Fc})$ is used as internal reference molecule; arrows show the sweep directions.

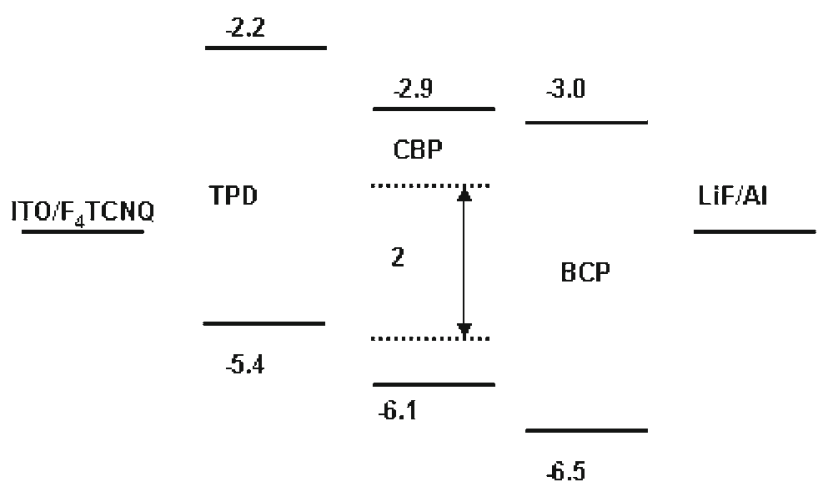

Figure 6. Energy level diagram of molecules used in multilayer OLED, ITO/F4 TCNQ/TPD/CBP+2/BCP/LIF/Al.

\subsection{Electroluminescence properties using Ir(III) complex as dopant molecules}

The electroluminescent properties and performance of 2 were studied in a multilayer OLED structure, $\mathrm{ITO} / \mathrm{F}_{4} \mathrm{TCNQ}(20 \AA) / \mathrm{TPD}(500 \AA) / \mathrm{CBP}+2(400 \AA) / \mathrm{BCP}$ $(60 \AA) / \mathrm{LiF}(15 \AA) / \mathrm{Al} . \mathrm{F}_{4} \mathrm{TCNQ}, \mathrm{TPD}, \mathrm{BCP}, \mathrm{LiF}$ and $\mathrm{Al}$ were successively deposited onto the patterned ITO. The device area was $2 \mathrm{~mm}^{2}$. The HOMO-LUMO energy levels of all the materials used in the device are shown in Figure 6 in the same order as arranged in the device. The dashed line shows the energy levels of the Ir complex 2, which is the dopant in CBP. The functions of the various layers are as follows. $\mathrm{F}_{4}$ TCNQ facilitates hole injection from ITO into TPD. BCP and LiF facilitate electron injection and electron transport to the active layer of CBP doped with 2. In addition, BCP serves as a hole blocking layer and TPD as an electron blocking layer. Thus, electron-hole recombination is expected to occur in the CBP. 


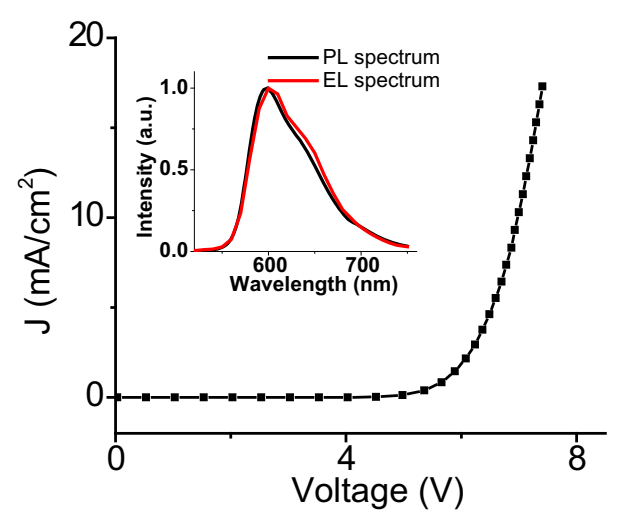

Figure 7. Current-Voltage characteristics of the device ITO/F 4 TCNQ/TPD/CBP+2/BC $\mathrm{P} / \mathrm{LIF} / \mathrm{Al}$. The inset shows the electroluminescence spectrum of the device and photoluminescence spectrum of Ir complex 2 .
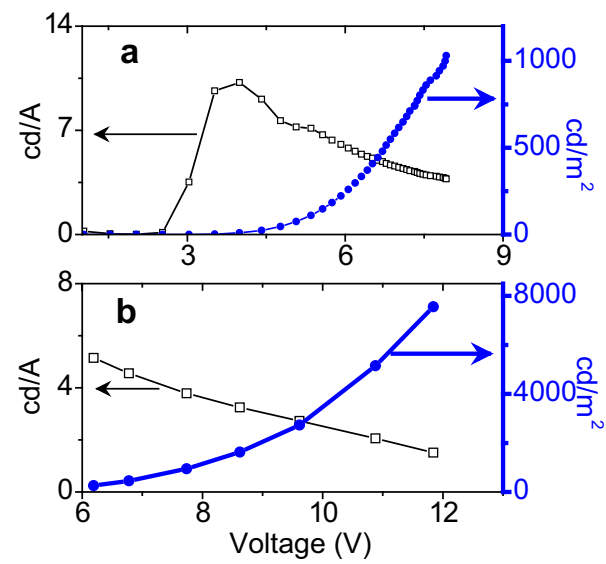

Figure 8. Light intensity $\left(\mathrm{cd} / \mathrm{m}^{2}\right)$ and current efficiency (cd/A) behaviour of OLED device, ITO/F4TCNQ/TPD/CBP+2/ $\mathrm{BCP} / \mathrm{LIF} / \mathrm{Al}$. (a) at low applied voltage; (b) at high applied voltage.

The I-V and electroluminescence characteristics of the phosphorescent OLED are shown in Figure 7. The inset shows the electroluminescence spectrum of the device and photoluminescence of $\mathbf{2}$ when doped in CBP as host. The electroluminescence spectrum overlaps onto the photoluminescence spectrum which suggests that all the emission is coming from the Iridium complex 2. The turn-on voltage of the device was at 4.5 V. Figure 8 shows that the light intensity continuously increased with applied voltage whereas the current efficiency is $\sim 7.0 \mathrm{~cd} / \mathrm{A}$ at a brightness of $\sim 100 \mathrm{~cd} / \mathrm{m}^{2}$. The highest brightness was measured to be $7600 \mathrm{~cd} / \mathrm{m}^{2}$.

It is worth mentioning that the performance of the device using 2 was not optimized for different doping ratios. This and the measurements of electroluminescence characteristics of other Ir complexes are in progress.

\section{Conclusions}

A series of new Ir(III) complexes of 1-phenylisoquinoline derivatives were synthesized and characterized. Photophysical studies of these complexes indicated emission in the orange to the deep red region. Electrochemical properties were used to determine the HOMO levels. The energy levels and emission quantum yields of these Ir complexes suggest that these molecules can serve as red emitting dopants in OLEDs. The OLED prepared using one of the molecules showed high brightness and current efficiency.

\section{Supplementary information (SI)}

${ }^{1} \mathrm{H}-\mathrm{NMR}$ and ${ }^{13} \mathrm{C}-\mathrm{NMR}$ spectra (Figures S1-S7), MA LDI mass spectra (Figures S9 and S10), PL decays (Figure S8), and cyclic voltammograms of the Ir complexes (Figure S11) are available at www.ias.ac.in/chemsci.

\section{Acknowledgements}

We thank the national facility for high field NMR at TIFR for NMR spectra. We also gratefully thank Prof. K. L. Narasimhan and Mr. Meghan Patankar for their help in the fabrication, measurements and interpretation of OLEDs. F.A. thanks DST for INSPIRE fellowship.

\section{References}

1. Xiao L, Chen Z, Qu B, Luo J, Kong S, Gong Q and Kido J 2011 Recent progresses on materials for electrophosphorescent organic light-emitting devices Adv. Mater. 23 926

2. Sun Y R, Giebink N C, Kanno H, Ma B W, Thompson M E and Forrest S R 2006 Management of singlet and triplet excitons for efficient white organic light-emitting devices Nature $\mathbf{4 4 0} 908$

3. Adachi C, Baldo M A, Forrest S R, Lamansky S, Thompson M E and Kwong R C 2001 High efficiency red electro-phosphorescence devices Appl. Phys. Lett. 78 1622

4. Fan C, Zhu L, Jiang B, Li Y, Zhao F, Ma D, Qin J and Yang C 2013 High Power Efficiency Yellow Phosphorescent OLEDs by Using New Iridium Complexes with Halogen-Substituted 2-Phenylbenzo $[d]$ thiazole Ligands J. Phys. Chem. C 11719134

5. Kadashchuk A, Skryshevski Y, Vakhnin A, Toliautas S, Sulskus J, Augulis R, Gulbinas V, Nespurek S, Genoe J and Valkunas L 2014 Highly Efficient Intrinsic Phosphorescence from a $\sigma$-Conjugated Poly(silylene) Polymer $J$. Phys. Chem. C 11822923

6. Colombo M G, Hauser A and Gudel H U 1993 Evidence for strong mixing between the LC and MLCT excited states in bis(2-phenylpyridinato-C2,N')(2,2'bipyridine)iridium(III) Inorg. Chem. 323088 
7. Baldo M A, Thompson M E and Forrest S R 2000 Highefficiency fluorescent organic light-emitting devices using a phosphorescent sensitizer Nature $\mathbf{4 0 3} 750$

8. Tokitoa S, Iijima T, Suzuri Y, Kita H, Tsuzuki T and Sato F 2003 Confinement of triplet energy on phosphorescent molecules for highly-efficient organic blue-lightemitting devices Appl. Phys. Lett. 83569

9. Adachi C, Baldo M A, Thompson M E and Forrest S R 2001 Nearly 100\% internal phosphorescence efficiency in an organic light-emitting device J. App. Phys. 905048

10. Williams E L, Haavisto K, Li J and Jabbour G E ExcimerBased White Phosphorescent Organic Light-Emitting Diodes with Nearly 100\% Internal Quantum Efficiency 2007 Adv. Mat. 19197

11. Lamansky S, Djurovich P, Murphy D, Abdel-Razzaq $\mathrm{F}$, Lee $\mathrm{H}$ E, Adachi C, Burrows $\mathrm{P}$ E Forrest S R and Thompson M E 2001 Highly phosphorescent biscyclometalated iridium complexes: synthesis, photophysical characterization, and use in organic light emitting diodes J. Am. Chem. Soc. 1234304

12. Kappaun S, Sax S, Eder S, Moller K C, Waich K, Niedermair F, Saf R, Mereiter K, Jacob J, Mullen K, List E J W and Slugove C 2007 Quinolinolates as Ligands for Luminescent Cyclometalated Iridium Complexes Chem. Mat. 191209

13. Chen H-Y, Yang, C-H, Chi Y, Cheng Y-M, Yeh Y-S, Chou P-T, Hsieh H-Y Liu C-S, Peng S-M and Lee G-H 2006 Room-temperature NIR phosphorescence of new iridium (III) complexes with ligands derived from benzoquinoxaline Can. J. Chem. 84309

14. Hanson K, Tamayo A, Diev VV, Whited M T, Djurovich P I and Thompson M E 2010 Efficient DipyrrinCentered Phosphorescence at Room Temperature from Bis-Cyclometalated Iridium(III) Dipyrrinato Complexes Inorg. Chem. 496077

15. Hofbeck T and Yersin H 2010 The Triplet State of facIr(ppy) 3. Inorg. Chem. 499290

16. Liu T, Xia B-H, Zhou X, Zhang H-X, Pan Q-J and Gao J-S 2007 Theoretical Studies on Structures and Spectroscopic Properties of Bis-Cyclometalated Iridium Complexes Organometallics 26143

17. Adachi C, Kwong R C, Djurovich P, Adamovich V, Baldo M A, Thompson M E and Forrest S R 2001 Endothermic energy transfer: A mechanism for generating very efficient high-energy phosphorescent emission in organic materials Appl. Phys. Lett. 792082

18. Okada S, Okinaka K, Iwawaki H, Furugori M, Hashimoto M, Mukaide T, Kamatani J, Igawa S, Tsub- oyama A, Takiguchi T and Ueno K 2005 Substituent effects of iridium complexes for highly efficient red OLEDs Dalton Trans. 91583

19. Park G Y, Seo J-H, Kim Y K, Kim Y S and Ha Y 2007 Efficient Red Electro-phosphorescent Devices Based on Iridium Complexes of Fluorinated 1-Phenylisoquinoline Jap. J. Appl. Phys. 462735

20. Tsuboyama A, Iwawaki H, Furugori M, Mukaide T, Kamatani J, Igawa S, Moriyama T, Miura S, Takiguchi T, Okada S, Hoshino M and Ueno K 2003 Homoleptic Cyclometalated Iridium Complexes with Highly Efficient Red Phosphorescence and Application to Organic Light-Emitting Diode J. Am. Chem. Soc. 125 12971

21. Anzenbacher Jr. P, Montes V A and Takizawa S Y 2008 High-purity white light from a simple single dopant host-guest white organic light-emitting diode architecture Appl. Phys. Lett. 93163302

22. Agarwal N and Nayak P K 2008 Synthesis, characterization, photophysical and electrochemical properties of new phosphorescent dopants for OLEDs Tetrahedron Lett. 492710

23. Miyaura N 2004 In Metal- catalysed cross coupling reactions A De Meijere and F Diederich (Eds.) (Weinheim: Wiley-VCH)

24. Kotha S, Lahiri K and Kashinath D 2002 Recent applications of the Suzuki-Miyaura cross-coupling reaction in organic synthesis Tetrahedron $\mathbf{5 8} 9633$

25. Frisch M J et al., 2004 Gaussian 03, revision C.02; Gaussian, Inc.: Wallingford, CT.

26. Runge E and Gross E K U 1984 Density functional theory of time dependent systems Phys. Rev. Lett. 52 997

27. Kubin R F and Fletcher A N 1983 Fluorescence quantum yields of some rhodamine dyes J. Lumin. 27 455

28. Mishra A, Nayak P K, Ray D, Patankar M P, Narasimhan K L and Periasamy N 2006 Synthesis and characterization of spin-coatable tert-amine molecules for holetransport in organic light-emitting diodes Tetrahedron Lett. 474715

29. Nayak P K, Agarwal N, Ali F, Patankar M P, Narasimhan K L and Periasamy N 2010 Blue and white light electroluminescence in a multilayer OLED using a new aluminium complex J. Chem. Sci. 122847

30. Gritzner G and Kuta J 1984 Recommendations on reporting electrode potentials in Nonaqueous solvents Pure Appl. Chem. 56461 